\title{
Strategic Agility and Its Impact on the Competitive Capabilities in Iranian Private Banks
}

\author{
Nikoo Tabe Khoshnood ${ }^{1} \&$ Sina Nematizadeh ${ }^{2}$ \\ ${ }^{1}$ Department of Executive management, central Tehran branch, Islamic Azad University, Iran \\ ${ }^{2}$ Faculty of Commercial Management Department, Central Tehran Branch, Islamic Azad University, Iran \\ Correspondence: Nikoo Tabe Khoshnood, Faculty of Management, Central Tehran Branch, Islamic Azad \\ University, Tehran, Iran. Tel: 982-122-763-303. E-mail: nikoo.khoshnood@gmail.com
}

Received: December 7, 2016

Accepted: January 20, 2017

Online Published: January 26, 2017

doi:10.5539/ijbm.v12n2p220

URL: http://dx.doi.org/10.5539/ijbm.v12n2p220

\begin{abstract}
Developing capabilities of agility, rapid responsiveness and adaptation to environmental changes are known as tools to gain competitive advantage. Strategic agility is a developed type of agility that in addition to rapid response pays specific attention to strategic aspects and predicting changes in the environment before they occur. Most of the studies in the field of agility and competitive advantage have focused on productivity and agility of supply chain. And a small number of studies have assessed the determinants of strategic agility and its impact on financial, competitive and operative factors organizations; therefore, having the awareness of both this issue and also the importance of competitiveness in the current banking system, in this research we have tried to explain the concept of strategic agility and its determinants, and to reveal its importance in the banking sector and to investigate its impact on the competitive capabilities of the private banks in Iran. In terms of its aim, this study is an applied one, and regarding the data collection, it is descriptive- correlational. The statistical population of this research consists of managers and experts working in the Iranian private banks. A total of 150 managers and experts from the banks have formed the study sample. In this study, first based on conducted studies, a model was developed to study the effect of strategic agility on competitive capabilities, and then, by using the tests of confirmatory factor analysis, Pearson structural equation modeling and correlation, this model was reviewed and approved. The results indicate that strategic agility has had significant impact on the competitive capabilities of the private banks in Iran. Furthermore, among the dimensions of strategic agility, clarity of vision is the most influential factor in the competitive capabilities.
\end{abstract}

Keywords: agility, strategic agility, competitive capabilities

\section{Introduction}

Today's business environment, due to globalization, technological innovation, reduction in products' life cycles and changing needs of customers, is quickly changing and difficult to be predicted. Agility, or in other words, the ability to respond and adapt quickly and effectively to unforeseen changes in the business environment, is a key competitive advantage in the market. (Ngai et al., 2011; Sharifi \& Zhang, 1999; Ganguly et al., 2009) Another issue which has doubled the importance of agility is this fact that today environmental changes have become faster and more complex than the past. From a variety of agility types, strategic agility is a new topic, which has attracted researchers in recent years (Long, 2000; Horney, 2007; Ojha, 2008.) In the $21^{\text {st }}$ century organizations need to successfully monitor and foresee the business environment path in order to adapt themselves to it. Products and their services must be tailored to the clientele's demand, and in some cases they must stimulate this demand from customers, while this demand is dependent on strategic agility. (Horney, 2007) In other words, companies' strategic agility directs them toward having internal view in order to obtain the necessary competence to compete, and having external view to take advantage of opportunities emerging from the change. (Long, 2000) Iran's banking industry in recent decades has moved toward competitiveness; today, with the increasing competition in the Iranian banking system, banks adopt different ways to increase or at least maintain their market share. Banks in this regard, due to their competitive advantages and strengthening them, can greatly guarantee their success in competition with other competitors.

In the present era creating strategic agility is a challenge which most organizations and businesses are not successful in handling and even some companies are not able to maintain it after the acquisition and with the 
passage of time due to excessive focus on growth and success and forgetting the need for agility, they lose their ability to lose; Therefore, organizations need to continually be aware of their strategic agility capabilities as a dynamic ability through performing assessment of it. Because according to the resource- oriented approach, a scarce resource, is impossible to imitate and irreplaceable and it helps a company to gain and maintain competitive advantage (Ojha, 2008).

\section{Theoretical Framework}

\subsection{Strategic Agility}

For the first time in 1991 the term agility was applied by researchers at the University of Li High to describe a flexible manufacturing system that has necessary capabilities to meet the rapidly changing needs of the market and it can respond to customers' demands in time. Extensive review of the agility's literature shows that an agile organization can be successful in competitive environment through the abilities of responsiveness, competence, flexibility and speed so that achieve competitive advantage in the market. (Li et al. 2006, Yusuf et al., 2012; Sharifi, zhang , 1999) Agility directly affects the company's ability to produce and distribute new products and cost effectiveness. Reduction in production costs, increasing customer satisfaction, phasing out of activities not having value-added and increasing competitiveness are the benefits that can be achieved through strategies of agility. (Bottani, 2009)

Definitions of agility are more focused on the concepts of the agility of production and supply chain, and they show that agility is a local capability focusing on internal processes and the policies of an enterprise and the reactive nature against changes. (Ganguly et al 2009; Ojha, 2008) However, increasing competition on a global scale, the growing rate of speed and complexity of changes and the increasing importance of knowledge in today's world are such that the reactive nature of agility is not enough alone. Today, not only must organizations think beyond adapting to change or responding to it, but also before the change, they must implement the changes in their business models and be after taking advantage of the potential opportunities. (Doz, Kosonen, 2008; Long, 2000)

Gradually, a wider range of definitions of agility were offered by some authors, who corrected some errors in reactive definition of agility. Ganguly et al. (2009) defined agility as a concept consisting of two components: responsiveness and knowledge management, and Matyakalan and his colleagues interpret agility as the ability of an organization to detect changes through the opportunities and threats existing in the business environment, and to give rapid response through the recombination of resources, processes and strategies; and in this definition, the strategic aspect has been added to operational aspect of the concept of agility.(Ganguly et al., 2009). Thus, in literature a new kind of agility developed, and today a new paradigm called strategic agility is emerging. Strategic agility requires simultaneously being agile and strategic. Being strategic means predicting changes and leveraging our own merits in order to overcome the change and agility means being responsive and agile. As a result, the agility, from strategic aspect, means being proactive in anticipating change and, from strategic aspect, responding to the change. Strategic agility is a concept that in some ways differs from the classic strategy approach; so that Doz and Sunni (2008) have argued that the life of strategic planning, in the conventional sense that a company formulates its vision and strategy for the next five to ten years and follow it, has been ended. Today, we must be on alert at every moment in order to be able to quickly restore and shift our strategy. They define strategic agility as the ability to modify or restore and recreate the dynamic and strategy of a company at the time of changing business environment. This ability is obtained by continuous predicting in addition to the modifying and adjusting the trends and clientele needs without giving up and abandoning the vision of the company. And it is known as a tool for organizations' survival and in markets defined by growth and systematic interdependence and rapid change. (Doz \& Kosonena, 2008) (Stratovation Consulting Inc. 2006) defines Strategic agility as the ability of a company to modify and adjust its path without losing sight of its long-term vision that is important for the today new economy. In addition, this institution defines strategic agility as a process in progress for an organization to proactively anticipate change and fast exploitation for significant competitive advantage.

Dove (2001) explained the Strategically-directed agility as change management skills. Skill is changing of a merit that allows an organization to apply knowledge as effective manner. Skill of changing helps organizations to achieve two objectives: (A) ensuring the effectiveness and feasibility (skill of reactive changes achieving market leadership (skill of active change) it should be noted that this skill allows any organization to effectively manage knowledge and apply it. (Dove, 1996; Dove, 2001); Thus, agility is seen as a dynamic capability has emerged from the strategies of knowledge production helping organizations handle change management better. (Sambamurthy et al., 2003) 
In connection with the models of strategic agility, it must be emphasized that in the literature, these models have been conceptualized in various ways. Doz and Kosonen have conceptualized strategic agility in terms of three dimensions: strategic sensitivity, collective commitment and fluidity of resources. Consulting Group offered a four-dimension definition of similar to the concept of strategic agility suggested by Daz and Kesnen, including Sensitivity to the opportunity, unity of leadership, fluidity of resources and Organizational Elasticity. (Implement Consulting Group, 2013) Mionjer adopts seven indicators to assess the strategic agility of the supply chain that are: 1- The ability to promptly detect changes. 2) Partners ability to make quick collective decisions.

3) The ability to respond quickly to changes, 4) Using information technology to share data, 5) Process integration and network coordination. 6) Product development with collaboration between partners, 7) a network thriving due to the strength of the partners (Mavengere, 2009). Long (2000), based on seven dimensions : clarity and lucidity of vision, clientele knowledge, understanding of fundamental capabilities, choosing strategic targets and objectives, shared responsibility, the knowledge of competitors, and taking action measured strategic agility. Ojiha (2008) believes that two dimensions of the knowledge of customers and competitors reflect the competency of market high sensitivity that can be used to achieve strategic agility, which are not included in the dimensions of strategic agility; Thus, only five dimensions of clarity and lucidity of vision, understanding of the fundamental capabilities, selecting strategic targets and objectives, shared responsibilities and taking action reflect strategic agility. Clarity of vision and understanding of the fundamental together provide the essential compound "the speed and stability "needed for an organization strategic agility. If an organization is not aware of its basic capabilities, it pursues opportunities which it is not prepared to take advantage of. Clarity and lucidity of vision provides the necessary speed to execute; an organization focuses on all its value chain partners only when it is fully aligned and motivated to exploit the opportunities associated with the organization. The ability to select strategic targets and objectives helps an organization to modify, improve or develop its capabilities in order to coordinate existing and emerging opportunities. (Long, 2000) Shared responsibility is a broad measure up to which the organization's relationship with the clients helps create value. The relationship between an organization and its value chain partners can generate value, and in addition to that, it can destroy the value; the roles of value creation include: partner, generating ability and narrating the truth, While the roles which destroy the value are: savior, causing dependence and colluding (Carucci \& Tetenbaum, 2000) The roles generating value, in comparison to the roles which destroy the value, are different regarding the amount of shared responsibility in a relation. the proportion of shared responsibility in a relation for the roles producing the value is high and for roles destroying value it is low, which is similar to the concept of strategic agility offered by (Sambamurthy et al. 2003). It means that a company simultaneously choses all components of its value chain network, production and exploitation of knowledge. Taking action reflects the degree up to which a company accepts the random actions reveal as the opportunities which make them seen; in other words taking action reflects the organization speed in having reaction. In this study the strategic agility has been measured based according to the model provided by Ojha (2008) based on five dimensions: clarity and lucidity of vision, understanding of fundamental capabilities, selecting strategic targets and objectives, shared responsibility, and taking action.

\subsection{Competitive Capabilities}

The notion of advantage is seated in two broad types of resources and capabilities. Resources that represent the assets controlled by the enterprise and are interpreted as the input of organizational processes, which is widely debatable in the resource- orientated approach; and capabilities that focus on the ability of a company in compounding, developing and adopting its resources to create competitive advantage (Ambe, I. M. 2010). Competitive capabilities make a supply chain of indicators showing the usefulness of strategic agility. These abilities should be immediate functional actions so that corrective action can be applied in a timely manner to improve supply chain performance. The overall List of competitive abilities for a company having strategic agility includes accountability, competence, flexibility and speed (Zhang \& Sharifi, 2000). The major driving forces in the strategic agility (Advanced production technology, better information systems, etc.) are increasing customer power and innovation speed; Hence, Competitive capabilities of company having strategic acceleration must be according to customer satisfaction and innovative educational perspectives; Therefore, customers attitude to services / products, timeliness, flexibility and value along with dimensions of learning and innovation, including innovation in product / process management, collaboration management, information flow, threats, etc., have become important competitive dimensions. (Ran, 2007) So the competitive capabilities of an organization can be interpreted as its ability to meet customers' expectations compared to the ability of its competitors. Literature review shows that researchers have used various dimensions in order to assess the competitive capabilities. In this study, based on an extensive review of literature, five indicators of quality, innovation, 
flexibility, reliability in the provision of services and cost leadership have been used in the assessment of competitive capabilities. (Rosenberg et al, 2003)

\section{Research and Development Model of Research Hypotheses}

As shown in Figure 1, in this research a model is proposed that relates strategic agility to competitive capabilities. The independent variable is strategic agility with five dimensions of clarity of vision, , understanding core capabilities, shared responsibility, selecting strategic targets, and taking action. The dependent variable is competitive capabilities which are measured with five indices of quality, innovation, flexibility, delivery reliability and cost leadership. This model has been developed based on an extensive review of agility literature and its impact on the competitive capabilities. In fact, this model was developed based on the belief that strategic agility as a dynamic ability and a concept derived from agility (strategic agility $=$ agility + strategic) is a key component in determining competitive success.

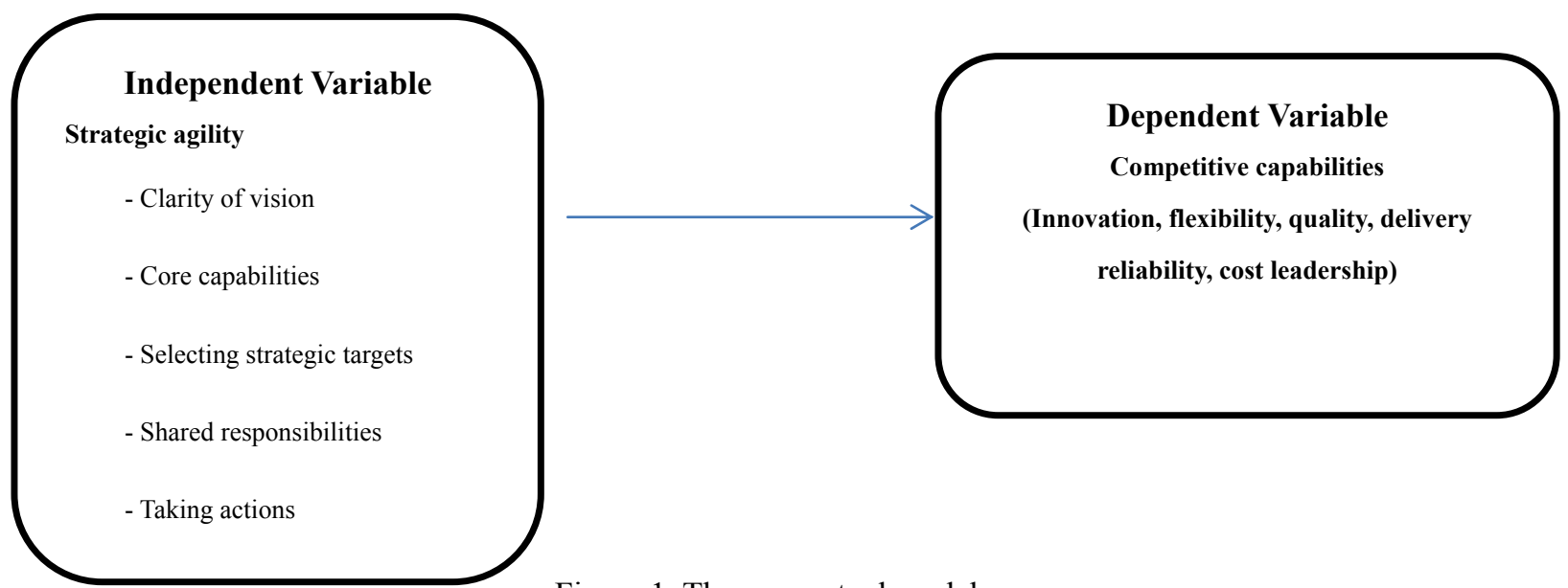

Figure 1. The conceptual model

Source: (studies conducted by the authors).

The research questions were raised as follows: 1) what are the dimensions of strategic agility and competitive capabilities? 2) Do the strategic agility and competitive capabilities have significant relation with each other? 3) Is strategic agility effective on competitive capabilities in the private banks of Iran? 4) Which dimensions of strategic agility have greatest impact on the competitive capabilities in the private banks of Iran? In this regard, the following hypotheses were proposed: 1) Strategic agility has a significant relationship with competitive capabilities private banks of Iran. 2) Clarity of vision has a significant, positive effect on the competitive capabilities in private banks of Iran. 3) Core capabilities has a significant, positive effect on the competitive capabilities of the private banks of Iran. 4) Shared responsibility has a significant, positive effect on the competitive capabilities in the private banks of Iran. 5) Selecting strategic targets has a significant, positive effect on the competitive capabilities in the private banks of Iran. 6) Taking action has a significant, positive effect on the competitive capabilities in the private banks of Iran.

In order to test the hypotheses, Pearson correlation test and structural equation modeling were applied.

\section{Research Method}

This study, in terms of its target, is an applied one and regarding the data collection, it is a descriptive -correlational study, by which we assess the relationship between strategic agility and competitive capabilities in the private banks of Iran. In order to collect data, a questionnaire developed by Ojha (2008) was used to assess the strategic agility and its dimensions. This questionnaire consists of 20 questions, which evaluates the five dimensions of strategic agility including: taking action, shared responsibility, understanding fundamental capabilities, selecting strategic targets and objectives, clarity and lucidity of vision in particular and on whole it studies the strategic agility construction. The questionnaire was graded using Five-item Likert scale from Strongly Disagree to completely agree. Furthermore, the questionnaire of competitive capabilities was designed by reviewing research literature and questionnaires used in the evaluation of competitive capabilities, and a total of 18 questions were adopted to assess the competitive capabilities.

The statistical population consists of managers and experts working in Iranian private banks. For example, at the 
level of banks, the following criteria were taken into account: Since the small private banks do not have any of these: widespread activity, organized structure and high ability to gain competitive capability, at first we tried, among private banks of Iran, to choose accredited and reputable banks that have widespread activity and their measured capabilities and indices are in proper level. A total of five private banks were examined and questionnaires were distributed among 150 managers and experts, and 101 completed questionnaires were collected.

In order to assess the validity of the questionnaire, the two methods of content-related validity and construction validity were used. To determine content-related validity, first the questionnaires, questions of the articles and studies which were related to research history were studies and reviewed. And then the research questionnaire was designed by taking advantage of the guidance provided by management professors. Construct validity has been investigated through confirmatory factor analysis. In Figure 2, Factor Loading of each item of strategic agility, and in Figure 3, Factor Loading of each item of competitive capabilities are shown respectively, which represent proper construct validity.

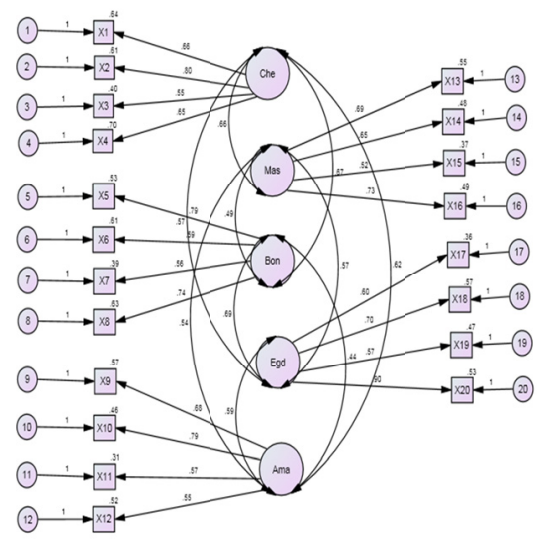

Figure 2. Standard estimates of confirmatory factor analysis (independent variables)

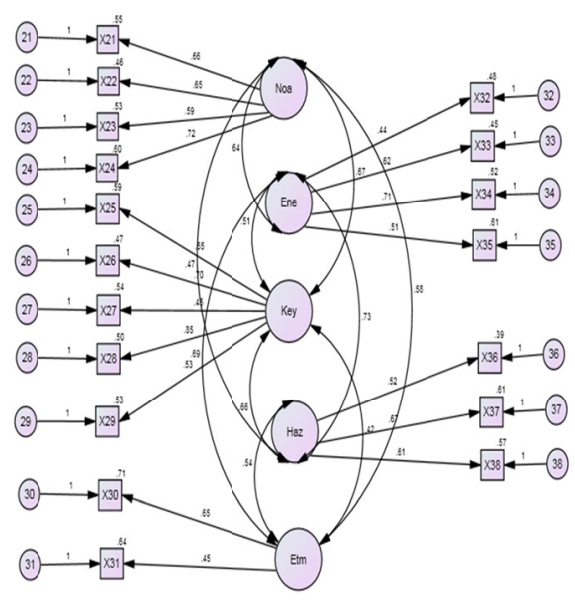

Figure 3. Standard estimates of confirmatory factor analysis of the dependent variable and it components

According to the conducted Factor analysis and NNFI $=0 / 94>0 / 9$ CFI $=0 / 96>0 / 9$ 'RMSEA $=0 / 061<0 / 08$ and $\mathrm{GFI}=0 / 93>0 / 9$, the model of strategic agility fits the data obtained from the questionnaire. Moreover, due to RMSEA $=0 / 059<0 / 08$ CFI $=0 / 97>0 / 9$ ،NNFI $=0 / 92>0 / 9$ and $\mathrm{GFI}=0 / 93>0 / 9$ the model of competitive capabilities has also a good fitting. In order to determine the reliability of the measurement tool, Cronbach's alpha has been used, which is higher than 0.7 for all of them, and it shows that the measurement tool has an acceptable reliability. 


\section{Findings}

Before testing the research hypotheses, in order to select the type of statistic to test the hypothesis, the assumption of normality of the data was analyzed using the Kolmogorov-Smirnov test. As shown in the table below, the Kolmogorov-Smirnov statistic value is between +1.96 and -1.96 . Moreover, the significance level for all variables is larger than 0.05 , As a result, the hypothesis which suggests normal distribution of strategic agility constructions and competitive capability has been confirmed, and taking action reflect strategic agility

\begin{tabular}{llll}
\hline Studied Variable & Kolmogorov-Smirnov & Asymp. Sig. (2-tailed) & Result \\
\hline clarity of vision & 1.386 & 0.073 & It is normal \\
core capabilities & 1.301 & 0.068 & It is normal \\
selecting strategic targets & 1.699 & 0.076 & It is normal \\
shared responsibilities & 1.179 & 0.118 & It is normal \\
Taking action & 1.186 & 0.128 & It is normal \\
innovation & 1.179 & 0.124 & It is normal \\
Service quality & 1.803 & 0.053 & It is normal \\
Reliability & 1.699 & 0.063 & It is normal \\
Flexibility & 1.386 & 0.086 & It is normal \\
Cost leadership & 1.301 & 0.088 & It is normal \\
\hline
\end{tabular}

In order to test research hypotheses, first we examined the relationship between variables of research, and Pearson correlation test, which is a parametric test, has been used for that purpose. The results of Pearson correlation test in Table 3 show that a significant, positive relationship exists between strategic agility and competitive capabilities at $99 \%$ confidence interval.

\begin{tabular}{|c|c|c|c|c|c|c|c|}
\hline Variable & 1 & 2 & & 3 & 4 & 5 & 6 \\
\hline Competitive capabilities & 1 & - & & - & - & - & - \\
\hline \multirow[t]{2}{*}{ clarity of vision } & $* *$ & 1 & & - & - & - & - \\
\hline & 0.61 & & & & & & \\
\hline \multirow[t]{2}{*}{ core capabilities } & $* *$ & $* *$ & & 1 & - & - & - \\
\hline & 0.44 & & 0.38 & & & & \\
\hline \multirow[t]{2}{*}{ selecting strategic targets } & $* *$ & $* *$ & & $* *$ & 1 & - & - \\
\hline & 0.57 & $\mathbf{0 . 3 0}$ & & 0.63 & & & \\
\hline \multirow[t]{2}{*}{ shared responsibilities } & $* *$ & $* *$ & & $* *$ & $* *$ & 1 & - \\
\hline & 0.48 & 0.54 & & 0.29 & 0.24 & & \\
\hline \multirow[t]{2}{*}{ Taking action } & $* *$ & $* *$ & & $* *$ & $* *$ & $* *$ & 1 \\
\hline & 0.49 & 0.43 & & 0.46 & 0.37 & 0.32 & \\
\hline
\end{tabular}

The correlation between research variables $(\mathrm{p}<0.01)$.

As the coefficients at $99 \%$ confidence interval show: there are significant relations between all the independent variables: clarity of vision, core capabilities, selecting strategic targets, shared responsibilities and taking action.

After ensuring that there is a significant relation between researches variables, in the following we wanted to investigate the nature of the type of relation and the direction of these variables impact in the form of conceptual models and to serve this purpose we have been used structural equation modeling. 


\subsection{The Estimate of Research Model}

the structural equation model and significant coefficient model for the research hypotheses both have been mentioned below and in the following we have assessed the appropriateness of the model and hypotheses testing according to the results.

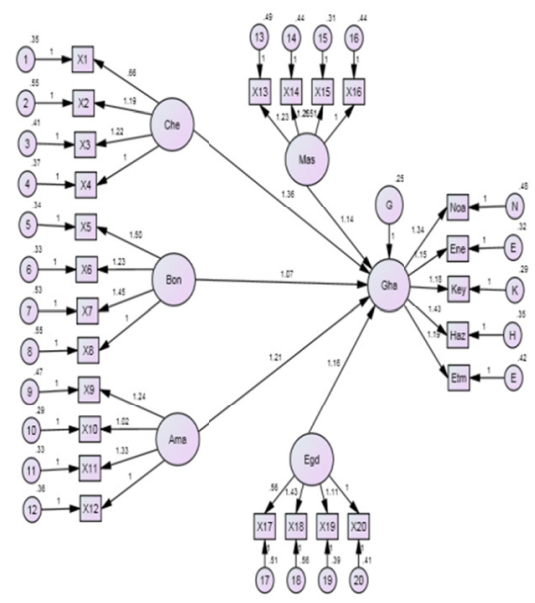

Figure 4. Graphical output of Standard model estimate

According to the indices presented in the table below and comparing it with the desired value for a fitted model, it shows the good fit of the research model.

\begin{tabular}{lcl}
\hline Fit index & Acceptance criterion & Value obtained for research model \\
\hline (Chi square) $\chi^{2}$ & $\chi^{2} / d f \leq 3$ & 2.45 \\
RMSEA & RMSEA $<0.08$ & 0.062 \\
NFI & NFI $>0.90$ & 0.92 \\
CFI & CFI $>0.95$ & 0.98 \\
GFI & GFI $>0.90$ & 0.93 \\
$\mathrm{X}^{2}=963.86$ & $\mathrm{df}=393$ &
\end{tabular}

Root Mean Square error of Approximation.

Normed Fit Index.

Comparative Fit Index.

Goodness of Fit Index.

Fit indices and the results obtained for research model.

The results obtained from Pearson correlation analysis confirm the significant relationship between independent variables of strategic agility and the dependent variable of competitive capabilities. Moreover, according to the results of the path coefficients and C.R. statistic (T statistic) shown in the following table and graphs of standard model coefficients, it has been found that variables clarity of vision, core capabilities, selecting strategic targets, shared responsibilities and taking action at significance level of 0.01 have significant, positive impact on the competitive capabilities so all the research hypotheses were confirmed. 


\begin{tabular}{|c|c|c|c|c|c|c|c|}
\hline $\begin{array}{l}\text { Standard } \\
\text { estimate }\end{array}$ & Significance level & T.C.R & $\begin{array}{l}\text { Standard } \\
\text { Error }\end{array}$ & Estimate & Independent & relation & dependent \\
\hline 0.432 & $* * *$ & 9.652 & 0.141 & 1.361 & clarity of vision & $-\rightarrow$ & $\begin{array}{l}\text { Competitive } \\
\text { capability }\end{array}$ \\
\hline 0.224 & $* * *$ & 8.523 & 0.126 & 1.074 & core capabilities & $-\rightarrow$ & $\begin{array}{l}\text { Competitive } \\
\text { capability }\end{array}$ \\
\hline 0.391 & $* * *$ & 8.797 & 0.138 & 1.214 & selecting targets & $-\rightarrow$ & $\begin{array}{l}\text { Competitive } \\
\text { capability }\end{array}$ \\
\hline 0.325 & $* * *$ & 9.201 & 0.124 & 1.141 & $\begin{array}{l}\text { Share } \\
\text { responsibility }\end{array}$ & $\rightarrow$ & $\begin{array}{l}\text { Competitive } \\
\text { capability }\end{array}$ \\
\hline 0.361 & $* * *$ & 10.468 & 0.111 & 1.162 & Taking actions & $-\rightarrow$ & $\begin{array}{l}\text { Competitive } \\
\text { capability }\end{array}$ \\
\hline
\end{tabular}

In the following, after examining the existence of significant differences between research variables in order to rank the variables, we used Friedman ranking test whose output has come in two tables 3 and 4 . Table 3 is related to the average rank of each of the variables and Table 4 is related to Statistical characteristic and Chi-square statistic of related variables.

Table 1. The mean of test variables ranks based on the Friedman Test

\begin{tabular}{ll}
\hline Variables & The mean of rank \\
\hline clarity of vision & 4.18 \\
selecting strategic targets & 4.12 \\
Taking action & 3.57 \\
shared responsibilities & 3.45 \\
core capabilities & 3.36 \\
\hline
\end{tabular}

Table 2. The significance level of Friedman Test

\begin{tabular}{ll}
\hline Statistical indices & Obtained Value \\
\hline Number & 101 \\
Chi-square & 89.149 \\
Degrees of freedom & 4 \\
Significance Level & 0.000 \\
\hline
\end{tabular}

According to the test outcome and as we can see in Table 3, among the independent variables: clarity of vision, having mean rank of 4.18, has the highest rank and after that selecting strategic targets, having mean rank of 4.12, taking actions, having mean rank of 3.57, shared responsibility, having mean rank of 3.45 core capabilities, having mean rank of 3.36 , are in the next ranks.

\section{Conclusion}

In this study, we have tried to assess and examine the relationship between the dimensions of strategic agility and competitive capabilities of Iranian private banks. The results of Factor analysis showed that in the Iranian private banks considering the dimensions of strategic agility, clarity of vision has the highest weight and core capabilities has the lowest weight. These results show that in the Iranian private banks, the managers are mostly concerned with having clarity and lucidity of vision of the looming end for the path which their organization has 
taken, and relatively they pay less attention to identifying their core capabilities. Furthermore, among competitive capabilities, cost leadership has had bigger factor loading, which reflects managers' focus on providing services at competitive prices in order to increase the competitive capabilities.

The results of correlation analysis and structural equation modeling conducted for strategic agility and competitive capabilities showed significant, positive correlation between them; thus, the primary hypothesis was confirmed, which is consistent with observations done by Ojha (2008), and it showed that strategic agility leads to improving the competitive capabilities. It also affirms the results provided by Oydijo (2012) stating Strategic agility improves the competitive performance of the Nigerian telecom firms. The results also showed that there are significant, positive relations between clarity of vision,core capabilities, selecting strategic targets, shared responsibilities and taking action and competitive capabilities. As a result, subsidiary hypotheses were confirmed, which can support Zelbest observations (2010); His observations showed that Agile manufacturing strategy directly affects the reasonable operating performance and having dependence on lower-cost, quality and quick response to changes in clientele demand have combined with necessary strategies to achieve competitive advantages.

Finally, Friedman ranking test showed that among the dimensions of strategic agility, clarity of vision has the greatest impact on the competitive capabilities. Selecting strategic targets, taking action, shared responsibility and core capabilities have hold the $2^{\text {nd }}$ to $5^{\text {th }}$ rank respectively. And from these outcomes it can be inferred that the managers of private banks, in order to improve their competitive capabilities, must emphasize clarity of vision in their banks and also codifying and selecting strategic targets prior to determining responsibility and collective commitment of the senior management team of the organization and taking any executive action.

\section{Recommendations}

Since the strategic agility is a dynamic capability, which according to a resource-reliant approach can be a Valuable, rare, irreplaceable, inimitable resource, and it can help a company gain and maintain competitive advantage (Ojha, 2008). Moreover, based on the obtained results, it could affect the competitive ability so managers working in studied banks should strive for bringing Strategic agility to their banks; therefore, according to these findings, recommendations are offered for improvement of Strategic agility dimensions of private banks operating in Iran as follows:

A- Developing and Clarity of strategic vision through a process of high quality dialogue with internal beneficiaries (employees and shareholders) and external beneficiaries (customers and suppliers). B- Permanent and continual Promoting and developing teamwork, and recovering and improving capabilities of senior management team in order to develop the morale of shared responsibility and creating cohesion among team members toward the achievement of strategic goals as to realize the strategic vision of the organization.

B- Developing shared responsibility and hence creating collective commitment among the members of senior management team through the development of communication and establishing trust. D- Progressing Fundamental capabilities of an organization through its emphasis on individual, team, and organizational learning, communicating with customers and suppliers and managing organizational Knowledge. E - Optimizing the defining of strategic objectives through the widespread development and application of information technology, decision making systems) (such as support system for making decisions) by the managers. FHaving speed in executive measures in order to demonstrate rapid reaction to changing market demands through having flexibility in the allocation and rearranging of resources and the creation of modular structures within an organization.

\section{References}

Ambe, I. M. (2010). Agile supply chain: Strategy for competitive advantage. Journal of Global Strategic Management, 7, 5-17. https://doi.org/10.20460/JGSM.2010415835

Bendoly, E., Rosenzweig, E. D., \& Stratman, J. K. (2007). Performance metric portfolios: A framework empirical analysis. Production and Operations Management, 16(2), 257-276. https://doi.org/10.1111/j.1937-5956.2007.tb00179.x

Carucci, R. A., \& Tetenbaum, T. J. (2000). The value-creating consultant. New York Harper Collins.

Davenport, H. T., Leibold, M., \& Voelpel, S. (2006). Strategic management in the innovation economy. A Joint Publication of Publicist Corporate Publishing and Wiley-VCH Verlag GbH \& Co KGaA.

Dove, R. (1996). Agile supply-chain management. Automotive Production, 1(5), 16-17.

Dove, R. (2001). Response ability: The language, structure and culture of agile enterprise. Journal of Knowledge 
Management, 1(3), 18-36.

Doz, Y. L., \& Kosonen, M. (2008a). Fast strategy: How strategic agility will help you stay ahead of the game. Strategy Magazine, 6(15), 6-10. Retrieved from http://www.sps.org.uk/

Doz, Y. L., \& Kosonen, M. (2008b). The dynamics of strategic agility: Nokia's rollercoaster Experience. California Management Review, 50(3), 95-118. https://doi.org/10.2307/41166447

Doz, Y. L., \& Kosonen, M. (2010). Embedding strategic agility: A leadership agenda for accelerating business model renewal. Long Range Planning, 43(2/3), 370-382. https://doi.org/10.1016/j.lrp.2009.07.006

Ganguly, A., Nilchiani, R., \& Farr, J. V. (2009). Evaluating agility in corporate enterprises. International Journal of Production Economics, 118(2), 410-423. https://doi.org/10.1016/j.ijpe.2008.12.009

Horney, N. F. (2007). Strategic Agility. Retrieved from American Management association. Retrieved from http://www.agilityconsulting.com

Implement Consulting Group. (2013). Strategic agility: What does it take to.

Long, C. (2000). You don't have a strategic plan: Good. Consulting to Management, 11(1), 35-42.

Mavengere, N. B. (2009). Strategic agility of supply chains (Master's dissertation). International Management of Information Technology, Turan Kauppakorkeakoulu, Turku School of Economics, Tilburg University, Netherlands.

Ojha, D. (2008). Impact of strategic agility on capabilities and financial performance (unpublished doctoral Dissertation). School of Clemson University, south Carolina, United States.

Oyedijo, A. (2012). Strategic Agility and Competitive Performance in the Nigerian Telecommunication Industry: An Empirical Investigation. American International Journal of Contemporary Research, 2(3), 30-37.

Ren, J., Yusuf, Y.Y., \& Burns, N. D. (2003). The effect of agile attributes on competitive priorities: A neural network approach. Integrated Manufacturing, 14(6), 489-497. https://doi.org/10.1108/09576060310491351

Rosenzweig, E. D., Roth, A. V., James, W., \& Dean, Jr. (2003). The influence of an integration strategy on competitive capabilities and business performance: An exploratory study of consumer products $\begin{array}{llll}\text { manufacturers. Journal of } & \text { Operations }\end{array}$ https://doi.org/10.1016/S0272-6963(03)00037-8

Sambamurthy, V., Bharadwaj, A., \& Grover, V. (2003). Shaping agility through digital options: Reconceptualizing the role of information technology in contemporary firms. MIS Quarterly, 27(2), 237-263.

Stratovation Consulting Inc. (2006). The importance of corporate agility. Harvard Business Review, 87(2), 78-88. Retrieved from http://www.Stratovation Consulting.com/

Zelbst, P. J., Green, K. W., Abshire, R. D., \& Sower, V. E. (2010). Relationships among market orientation, JIT, TQM, and agility. Industrial Management \& Data Systems, 110(5), 637-658. https://doi.org/10.1108/02635571011044704

Zhang, Z., \& Sharifi, H. (2000). A methodology for achieving agility in manufacturing organizations. International Journal of Operations and Production Management, 20(4), 496-512. https://doi.org/10.1108/01443570010314818

\section{Copyrights}

Copyright for this article is retained by the author(s), with first publication rights granted to the journal.

This is an open-access article distributed under the terms and conditions of the Creative Commons Attribution license (http://creativecommons.org/licenses/by/4.0/). 